\title{
A MODEL TO SIMULATE BEACH PROFILE EVOLUTION INDUCED BY STORMS
}

\author{
Jie Zhang, Lund University, jie.zhang@tvrl.Ith.se \\ Magnus Larson, Lund University, magnus.larson@tvrl.Ith.se \\ Zhenpeng Ge, East China Normal University, zhenpeng.ge@tvrl.Ith.se
}

\section{INTRODUCTION}

Beach profile change induced by storms is a common and complex process in coastal engineering. Storms often bring high water levels and large waves, which erode the berm and dune, carrying large quantities of sand offshore, often causing severe damage to coastal properties. Thus, considerable research has been carried out to determine storm impact. Early studies mainly focused on laboratory investigations and analysis of field data. Since the 1980's, many engineering numerical models of beach profile change have been developed. Kriebel and Dean (1985) proposed a model (EBEACH) to simulate the beach profile evolution with focus on dune erosion during storms, using the concept of an equilibrium beach profile (EBP). However, features such as bars and berms are not described in this model. Larson and Kraus (1989) developed an empirically based model (SBEACH) for describing the formation of bars and berms, also applying the EBP concept. Steetzel (1990) developed a model for cross-shore transport during severe storms that focuses on offshore transport and erosion. Johnson et al. (2012) developed a CS profile evolution model, CSHORE, that is mainly used to predict beach erosion under the combined effect of waves and currents. Although the model provided satisfactory performance in simulating measured berm and dune erosion in field applications, further improvements in dealing with the sediment transport in the intermittently wet-dry areas are desirable. At present, XBeach proposed by Roelvink et al. (2009) is the most popular and widely used model together with SBEACH. Although the objective of the XBeach model is to predict the profile evolution along the entire profile, i.e., both in the subaerial and subaqueous regions, the processes in the former region are less well described from a physics point of view compared to the latter. The response of the subaerial region in XBeach, including the foreshore, berm, and dune, relies on rather ad-hoc empirical sediment transport formulations. This study presents a profile evolution model that is based on the work by Larson et al. (2015). The emphasis of the model development is physically based descriptions of the subaerial profile response induced by storms. Focus of the model validation here is the berm and foreshore region.

\section{MODEL STRUCTURE}

Various modules are integrated in the present model to predict the profile response, including modules for wave transformation; mean water level change; cross-shore currents; sediment transport in the swash zone, inner and outer surf zone, and offshore zone; avalanching; and bed level change. The connections among the various modules are shown in Figure 1. The wave transformation module calculates wave and mean water level properties by using the phase-averaged random wave decay model developed by Larson (1995). The current module estimates the undertow velocity based on the equations proposed by Rattanapitikon and Shibayama (2000) expressed for random conditions. The sediment transport module calculates the transport rate in the offshore, surf, and swash zone employing the equations derived by Camenen and Larson $(2005,2008)$ and Larson et al. (2004). Each of these modules have previously been validated with both experimental and field data in a number of studies. However, the integrated model, including its further development, has not been tested and validated before.

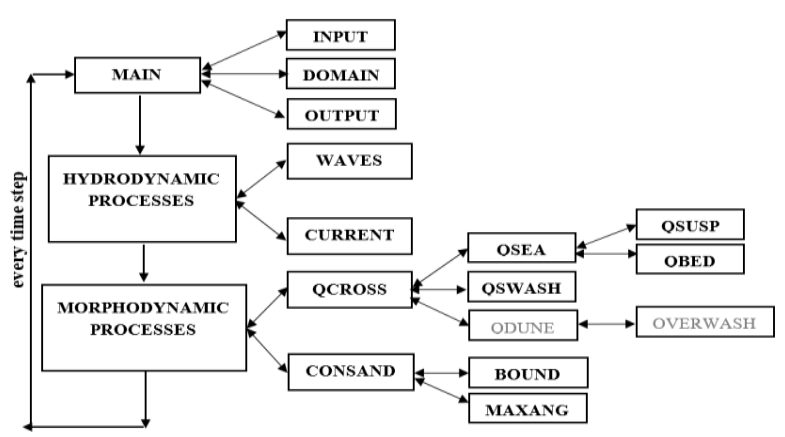

Figure 1 - Schematic of the connections among the various calculation modules in the numerical model of beach profile evolution.

\section{SELECTED RESULTS}

In order to validate the model, a number of simulation tests were carried out employing data from the SUPERTANK data collection project (Kraus and Smith, 1994). The SUPERTANK data involve a wide range of profile response cases for which detailed and comprehensive wave, water level, current, sediment concentration, and bed level change data are available. Four experimental cases encompassing three types of profile response, involving bar (ST_10), berm (ST_90), and offshore mound (ST_J0, ST_K0) evolution were chosen to calibrate and validate the model. Here, results from simulations for Cases ST_10, ST_90, ST_J0 and ST_K0 are presented in Figures $2-\overline{5}$, respectively. The same set of parameter values was used in all of the simulation cases displayed.

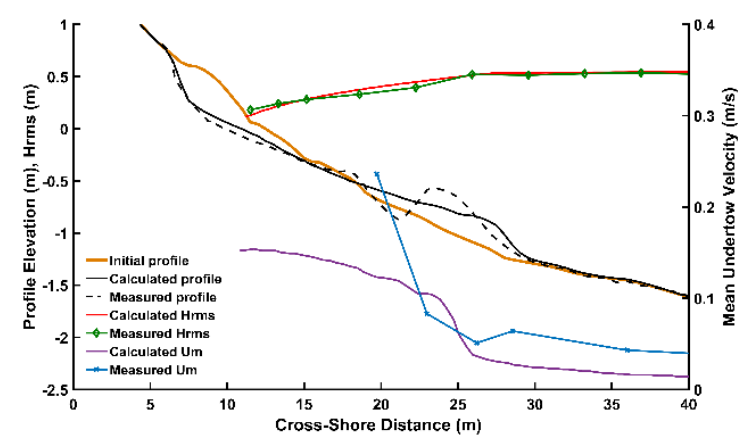

Figure 2 - Calculated and measured beach profiles, wave height $\left(H_{r m s}\right)$ and undertow velocity $\left(U_{m}\right)$ for Case ST_10 after $270 \mathrm{~min}$ of wave action. 


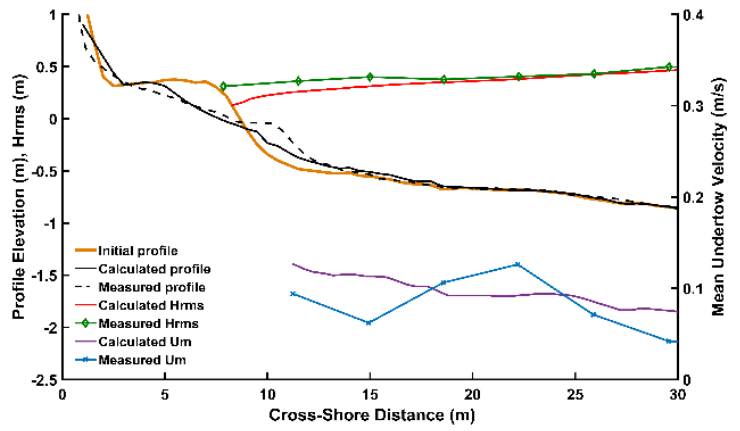

Figure 3 - Calculated and measured beach profiles, wave height $\left(H_{r m s}\right)$ and undertow velocity $\left(U_{m}\right)$ for Case ST_90 after $50 \mathrm{~min}$ of wave action.

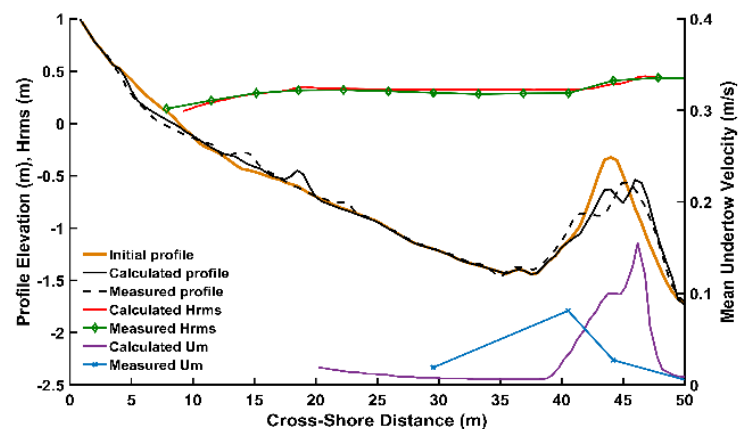

Figure 4 - Calculated and measured beach profiles, wave height $\left(H_{r m s}\right)$, and undertow velocity $\left(U_{m}\right)$ for Case ST_J0 after $150 \mathrm{~min}$ of wave action.

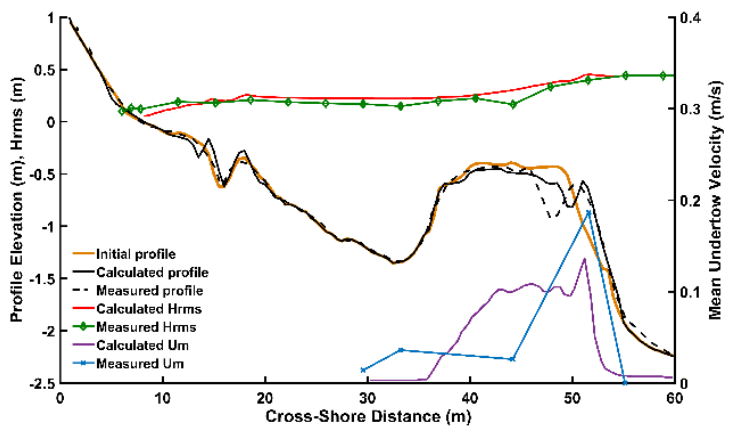

Figure 5 - Calculated and measured beach profiles, wave height $\left(H_{r m s}\right)$, and undertow velocity $\left(U_{m}\right)$ for Case ST_K0 after $220 \mathrm{~min}$ of wave action.

As shown in the figures, for the rms wave height, all cases showed good agreement between the measurements and calculations. In terms of profile evolution, satisfactory results were obtained by the model compared to the measured profiles, except locally. For example, the calculated bar is more subdued than the measured bar in Case ST_10, and the calculations display more erosion at the berm than the measurements in Case ST_90. Also, the calculated seaward location of the mound is somewhat overestimated compared to the measurements for both Cases ST_J0 and ST_K0. In order to quantify the model performance for beach morphology, the rms error (RMSE) and the Brier Skill Score (BSS) for each case were calculated; see Table 1. From the values in this table, it can be concluded that the model yields satisfactory results for simulating beach profile evolution, since all the values of BSS are larger than 0.6 (the qualification of BSS in predicting model performance will be shown in the full paper). Meanwhile, all the RMSE values representing the deviation between the measured profile and calculated profile are within the acceptable range, again indicating that the model can reproduce the observed profile evolution.

Table 1 - The RMSE and BSS for predicted beach profile evolution in each of the studied cases.

\begin{tabular}{lll}
\hline Case & RMSE & BSS \\
\hline ST_10 & 0.058 & 0.841 \\
ST_90 & 0.044 & 0.779 \\
ST_J0 & 0.062 & 0.689 \\
ST_K0 & 0.073 & 0.622 \\
\hline
\end{tabular}

With regard to the undertow, the results are not as good, but in general, the overall trend of the calculated undertow is in agreement with the measured velocity. Overall, the model displays quantitative skill in predicting beach profile evolution as well as the hydrodynamics.

However, some model limitations are worth noting; for example, this model is not yet able to calculate dune erosion and has not been validated with field data. Furthermore, the description of long waves associated with the swash zone is needed to be further improved. Thus, in the next step, the authors will integrate the dune erosion and overwash into the model, and validate it with appropriate field data.

\section{REFERENCES}

Camenen, B., Larson, M. (2005): A bedload sediment transport formula for the nearshore, Estuarine, Coastal and Shelf Science, 63(1-2), 249-260.

Camenen, B., Larson, M. (2008): A general formula for noncohesive suspended sediment transport, Journal of Coastal Research, 615-627.

Johnson, B. D., Kobayashi, N., Gravens, M. B. (2012): Crossshore numerical model CSHORE for waves, currents, sediment transport and beach profile evolution (No. ERDC/CHL-TR-12-22), ENGINEER RESEARCH AND DEVELOPMENT CENTER VICKSBURG MS COASTAL AND HYDRAULICS LAB

Kraus, N.C., Smith, J.M. (1994): SUPERTANK laboratory data collection project, TR-CERC-94-3, USACE-WES, Vicksburg, MS.

Kriebel, D. L., Dean, R. G. (1985): Numerical simulation of time-dependent beach and dune erosion, Coastal Engineering, 9(3), 221-245.

Larson, M. (1995): Model for decay of random waves in surf zone, Journal of waterway, port, coastal, and ocean engineering, 121(1), 1-12.

Larson, M., Erikson, L., Hanson, H. (2004): An analytical model to predict dune erosion due to wave impact, Coastal Engineering, 51(8-9), 675-696.

Larson, M., Kraus, N. C. (1989): SBEACH: numerical model for simulating storm-induced beach change, Report 1: Empirical foundation and model development (No. CERC-TR89-9), Coastal Engineering Research Center Vicksburg Ms.

Larson, M., Westergren, S., Hanson, H. (2015): Modeling beach profile response to varying waves and water levels with special focus on the subaerial region, The Proceedings of the Coastal Sediments 2015.

Rattanapitikon, W., Shibayama, T. (2000): Simple model for undertow profile, Coastal Engineering Journal, 42(1), 1-30. Roelvink, D., Reniers, A., Van Dongeren, A. P., de Vries, J. V. T., McCall, R., Lescinski, J. (2009): Modelling storm impacts on beaches, dunes and barrier islands, Coastal engineering, 56(11-12), 1133-1152.

Steetzel, H. J. (1990): Cross-shore transport during storm surges, Coastal Engineering Proceedings, 1(22). 